UCRL-ID-127766

\title{
Structural Stability of a Rectangular, Simply-Supported Beam Subject to a Sudden Air Temperature Change Next to One Surface
}

Charles S. Landram

July 3, 1997

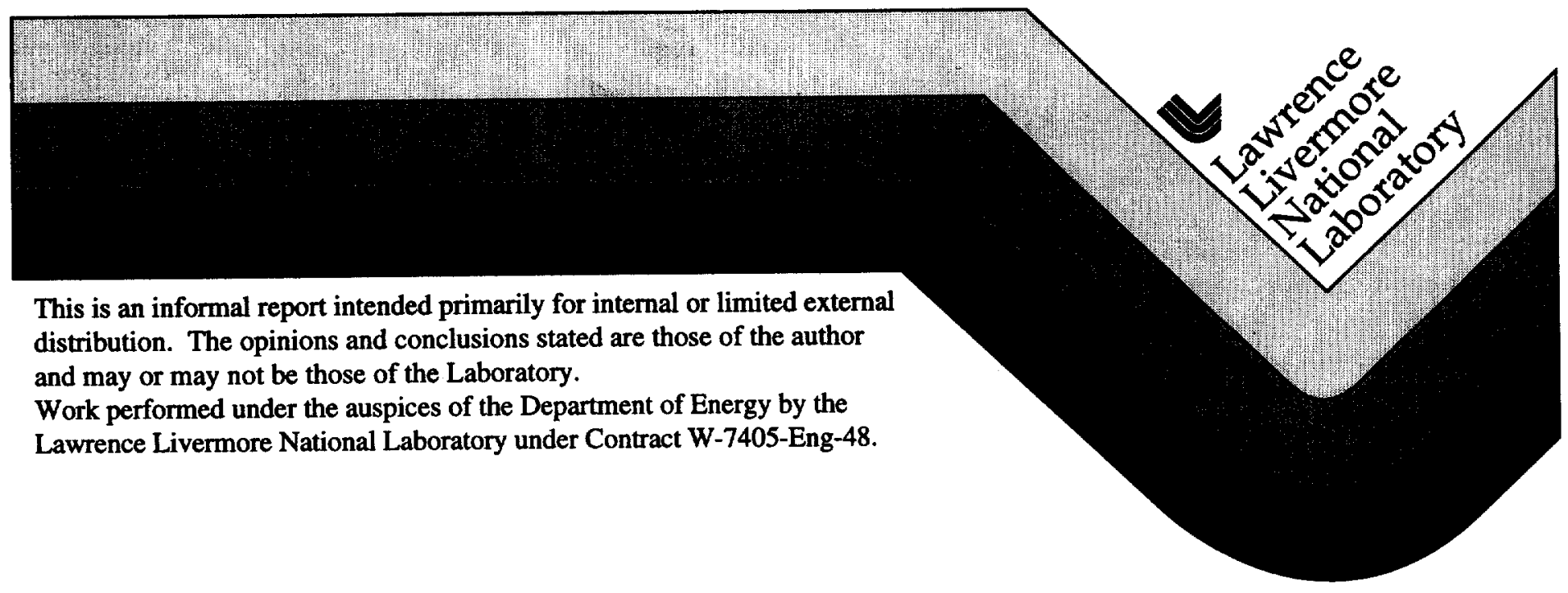


DISCLAIMER

This document was prepared as an account of work sponsored by an agency of the United States Government. Neither the Unitod States Government nor the University of California nor any of their employees, makes any warrenty, express or implied, or essumes any legal liability or responsibility for the accuracy, completeness, or usefulness of any information, apparatus, product, or process disclosed, or represents that its use would aot infringe privately owned rights. Reference herein to any specific commercial product, process, or service by trade name, trademark, manufacturer, or otherwise, does not necessarily constitute or imply its endorsement, recommendation, or favoring by the United States Government or the University of Califomia. The views and opinions of authors expressed herein do not necessarily state or reflect those of the United States Government or the University of California, and shall not be used for advertising or product endorsement purposes.

This report has been reproduced directly from the best available copy.

Available to DOE and DOE contractors from the Office of Scientific and Technical Information

P.O. Box 62, Oak Ridge. TN 37831

Prices available from (615) 576-8401, FTS 626-8401

Available to the public from the

National Technical Information Service

U.S. Department of Commerce

5285 Port Royal Rd.

Springfield, VA 22161 


\title{
Structural Stability of a Rectangular, Simply-Supported Beam Subjected to a Sudden Air Temperature Change Next to One Surface
}

\author{
Charles S. Landram \\ NTED
}

\section{SUMMARY}

For a simply-supported, rectangular beam suddenly heated on one of its surfaces by surrounding air, both elongational and flexural thermal distortions occur. For steel beams of order 10 to $30 \mathrm{~cm}$ thick and about $3 \mathrm{~m}$ long, flexural displacements, developing in minutes, occur much faster than elongational displacements which occur in hours. The rapid response of the flexural modes is caused by the early-time surface heating of the side of the beam exposed to the suddenly-heated, warmer air. The slower response of the elongation modes is a consequence of a much slower change in the average temperature of the beam. At a span of $3.05 \mathrm{~m}$, the maximum steady state flexural distortions in micrometers were $0.22,0.78$ and 1.56 for respective one-sided air temperature changes in degrees $C$ of $0.28,1$ and 2 .

\section{INTRODUCTION}

Thermal distortion of beamline optical systems can become a difficult problem when the displacements occur faster than times required for realignment. The response of most support structures is governed by the transient internal temperature field . In general there are two heat transfer modes that can introduce a temperature perturbation into a structure from a non-contacting heat source. One is thermal radiation, which is a surface to - surface net heat exchange originating from lights, pump housings, heated walls, camera housings and the like. The other is convection, set up, for example, by a convective plume from a heat source or simply by unsteady local air temperature variations inherent in air conditioning system design and control.

The present work considers the convective heating/cooling case. The purpose is to obtain the transient internal temperature distributions and the resulting distortions for simply-supported beam structures suddenly experiencing an air temperature change next to one surface.

\section{MODEL}

The model is illustrated in Fig. 1. Beam distortions caused by thermal disturbances will be greatest for simply supported beams (pin and roller). The most severe thermal case is for the air on the entire top surface of the beam to be suddenly raised in 
temperature with the opposite bottom surface of the beam continuing to be exposed to air maintained at the initial temperature. The situation is made even more severe by insulating the sides of the beam, which is equivalent to having the beam dimension w in Fig. 1 large in comparison to the thickness $2 \mathrm{c}$.

Once the air on the top surface is raised in temperature, two thermal distortions will commence, and these are governed by thermal convection at the surfaces and diffusion within the thickness of the beam. The top, heating faster than the bottom surface, will become convex and the bottom concave as illustrated in Fig. 1. The average temperature across the beam thickness will also increase, causing the beam to elongate.

\section{FORMULATION}

Based upon the model described above, the transient temperature field through the beam thickness is one-dimensional. Defining the excess temperature as $v(x, t)=T(x, t)-T o$, where $T$ and $T o$ are the beam and initial temperatures, respectively, gives the following formulation:

$$
\frac{\partial^{2} v}{\partial x^{2}}=\frac{1}{\alpha} \frac{\partial v}{\partial t}, x>0, \quad t>0
$$

subject to $v(x, o)=o$

$$
\begin{aligned}
& k \partial v / \partial x=h(\Delta T-v), \quad x=c, \quad t>0 \\
& k \partial v / \partial x=h v, \quad x=-c, \quad t>0
\end{aligned}
$$

where $\alpha, k$, and $h$ are respectively the beam's thermal diffusivity, conductivity and surface heat transfer coefficient. The slight difference in heat transfer coefficient between top and bottom surfaces for natural convection is ignored here. The value of air temperature change $\Delta \mathrm{T}$ is imposed parametrically.

Once the excess temperature $v$ is known, the instantaneous elongation of the beam is obtained from

$$
\begin{aligned}
& E=\alpha_{e} L V_{\text {avg }} \\
& V_{\text {avg }}(t)=\frac{1}{2 c} \int_{-c}^{c} v(x, t) d x
\end{aligned}
$$

where $\alpha_{e}$ and $\mathrm{L}$ are the coefficient of thermal expansion and beam span, respectively. The curvature of the beam can be obtained from Timoshenko and Goodier [1] or Benham and Hoyle [2] to write

$$
\frac{1}{R(t)}=\frac{3 \alpha_{e}}{2 c^{3}} \int_{-c}^{c} v(x, t) x d x
$$


where $\mathrm{R}$ is the radius of curvature. The flexural deflection $\mathrm{Y}$ can then be obtained from the deflection equation

$$
\frac{d^{2} Y}{d Z^{2}}=\frac{1}{R}
$$

subject to $\mathrm{Y}=0$ at $\mathrm{Z}=0$ and $\mathrm{L}$. The maximum deflection in bending occurs at $\mathrm{Z}=\mathrm{L} / 2$.

\section{SOLUTION}

The exact solution to eq. 1 , subject to the stated conditions, is given in Carslaw and Jaeger [3] and will not be repeated here. The solution $v(x, t) / \Delta T$ depends on three parameters, namely, $x / c$, the Fourier number, $\alpha t / c^{2}$ and the Biot number, $B=h c / k$. The Biot number $B$ is governed primarily by natural convection, and the largest value for $B$ for any of the cases that apply is less than 0.02 . For these small values of $B$, the two trigonometric eigenvalue equations in reference [3] simplify considerably. Consequently, the solution can be written to order of accuracy $\mathrm{B}^{2}$ as

$$
\begin{aligned}
& \frac{v(x, t)}{\Delta T}=\frac{1+B\left(1+\frac{x}{c}\right)}{2(1+B)}-\left[\frac{1-\frac{B}{2}\left(1-\frac{B}{3}\right)\left(\frac{x}{c}\right)^{2}}{2\left(1+\frac{B}{2}\right)\left[1-\frac{B}{2}\left(1-\frac{B}{3}\right)\right]}\right] e^{-B\left(1-\frac{B}{3}\right) \frac{\alpha x}{c^{2}}} \\
& +B\left\{\sum_{n=1}^{\infty} \frac{(-1)^{n} \sin \left(K_{n} \frac{x}{c}\right)}{K_{n}^{2}} e^{-K_{n}^{2} \frac{\alpha x}{c^{2}}}-\sum_{n=2}^{\infty} \frac{(-1)^{n-1} \cos \left(G_{n} \frac{x}{c}\right)}{G_{n}^{2}} e^{-G_{n}^{2} \frac{\alpha x}{c^{2}}}\right\}
\end{aligned}
$$

where $K_{n}=\left(\frac{2 n-1}{2}\right) \pi, \quad G_{n}=(n-1) \pi, \quad n=1,2,3, \ldots$

The second term in equation 5 is the first eigenfunction for the second series shown and has, to order $\mathrm{B}^{2}$ accuracy, the eigenvalue $[\mathrm{B}(1-\mathrm{B} / 3)]^{(1 / 2)}$. The average temperature for $\mathrm{B}<<1$ can then be evaluated from equation $2 \mathrm{~b}$ and is given by

$$
\frac{V_{\text {avg }}(t)}{\Delta t}=\frac{1}{2}\left(1-e^{-B \alpha t / c^{2}}\right)
$$

The curvature is evaluated from the integral given by equation 3 using the temperature distribution given by equation 5 . The solution to equation 4 then follows, and the maximum bending displacement at $\mathrm{Z}=\mathrm{L} / 2$ is obtained as

$$
Y_{\max }=\left(Y_{\max }\right)_{\text {steady }}\left(1-6 \sum_{n=1}^{\infty} \frac{e^{-K_{n}^{2} \alpha x / c^{2}}}{K_{n}^{4}}\right)
$$


where

$$
\left(Y_{\max }\right)_{\text {steady }}=\frac{h}{k} \frac{\alpha_{e} \Delta T}{16} L^{2}
$$

is the steady-state midspan deflection which agrees with that given in Roark and Young [4].

\section{RESULTS}

For the Biot number shown in Fig. 2, which applies to natural convection with a 20.4 $\mathrm{cm}$ thick steel beam, the temperature distribution is shown normalized to the top-sided air temperature change $\Delta \mathrm{T}$. About $1 / 3$ hour is required for the heat to diffuse across the thickness, at which time the top surface has increased in temperature by approximately $0.009 \Delta \mathrm{T}$. Since more complex geometries will require numerical treatments, a finitedifference calculation was performed for the conditions of Fig. 2 in order to assess potential difficulties in computing the small magnitudes of the temperature response (ordinates of Fig. 2).

No such difficulty was encountered. For the numerical treatment, a rather coarse grid was chosen, having four, equally-spaced interior points and two boundary points. The interior nodes were centrally differenced to second-order accuracy, and the boundary nodes, also of second order spatial accuracy, were treated by two separate methods. In one method a Taylors series was used to represent the spatial derivative at the boundaries, this involving the surface node and the two adjacent interior nodes. The other method created energy balances at the surfaces based upon fictitious nodes outside the computational domain. The resulting time-dependent first order differential equations were then solved by the fourth-order Runge-Kutta method with time steps of 0.01 in Fourier number.

As shown in Fig. 2, the two differencing methods overlap the exact solution (equation 5). The fictitious node method appears to produce better results in earlier times, while the Taylors series method performs better in later times. Since the exact temperature distribution was used to evaluate the results that follow, no further effort was expended to refine the numerical solution by adding more mesh points.

In Fig. 3, both the average temperature across the beam thickness and the difference in surface temperatures across the beam are plotted as a function of time. The surface temperature difference is seen to respond much faster than the average temperature. As a result, the flexural modes onset much sooner than the elongational modes as demonstrated in Fig. 4. There the deflections are normalized to their steady-state values (these resulting from a permanent air temperature increase applied above the top surface). The normalization of the ordinates of Fig. 4 is deceiving because the steady-state 
deflections in elongation tend to be much larger than those in flexure as illustrated in Fig. 5 .

The results of Figs. 4 and 5 are combined in Fig. 6 to obtain actual displacements per $\Delta \mathrm{T}$ rise in air temperature. Flexural displacements are seen to dominate those of elongation in times less than about one hour, flexural modes being fully developed in less than about one hour. Elapsed times greater than about 1.5 hours are required to have elongations the same size as maximum bending displacements for beam thicknesses greater than about $10 \mathrm{~cm}$. For a $10.2 \mathrm{~cm}$ thick, $3.05 \mathrm{~m}$ long simply-supported steel beam subjected to an air temperature change of $0.28 \mathrm{C}$ on one side, the maximum bending displacement is 0.22 microns and is achieved in about 20 minutes, and a midspan bending displacement of 0.11 microns is achieved in just 3 minutes. The most unstable modes are flexural and are driven by unequal heat loads across the beam. 


\section{References}

1. Timoshenko, S. and Goodier, J. Theory of Elasticity, McGraw-Hill, Third Edition, 1970, Chapter 13.

2. Benham, P. and Hoyle, R., Thermal Stress, Pitman and Sons LTD, London, 1964, Section 4.2.

3. Carslaw, H. and Jaeger, J. Conduction of Heat in Solids, Oxford Press, 2nd Edition, 1959, Section 3.11, case (viii).

4. Roark, R. and Young, W., Formulas for Stress and Strain, McGraw-Hill, 5th Edition, 1975. 


\section{Nomenclature}

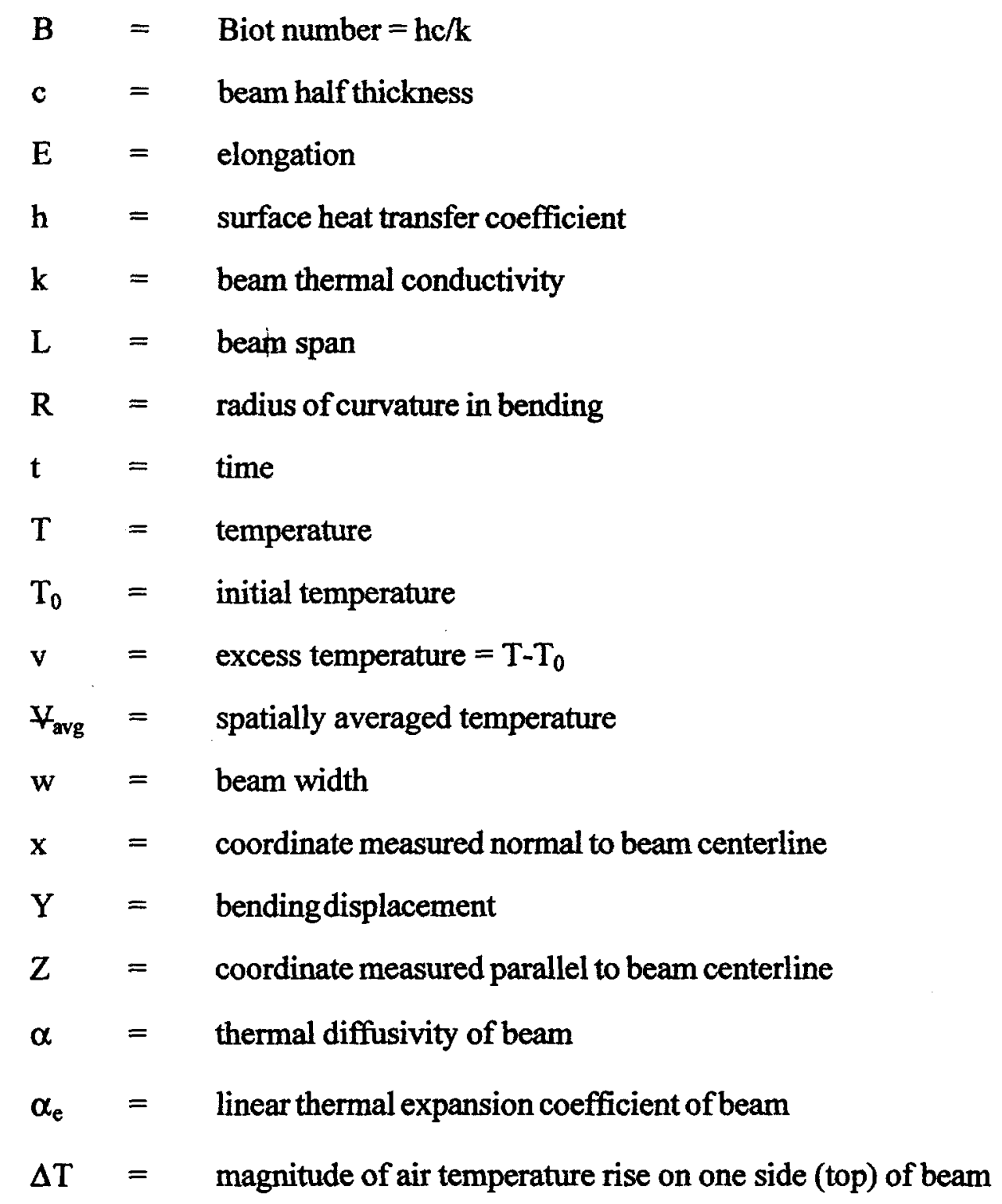


Figure 1. Model
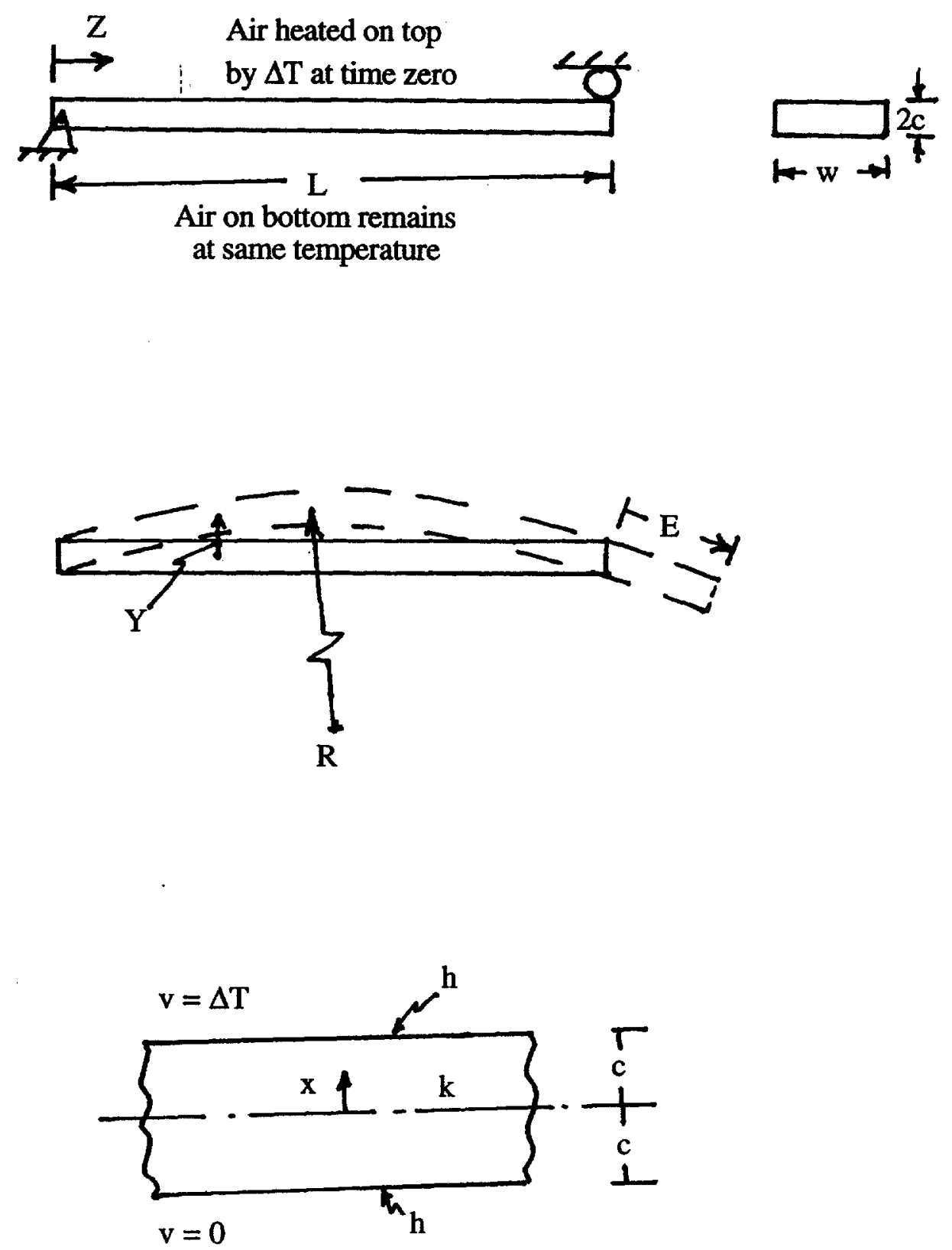
Figure 2. Unsteady beam temperature distribution

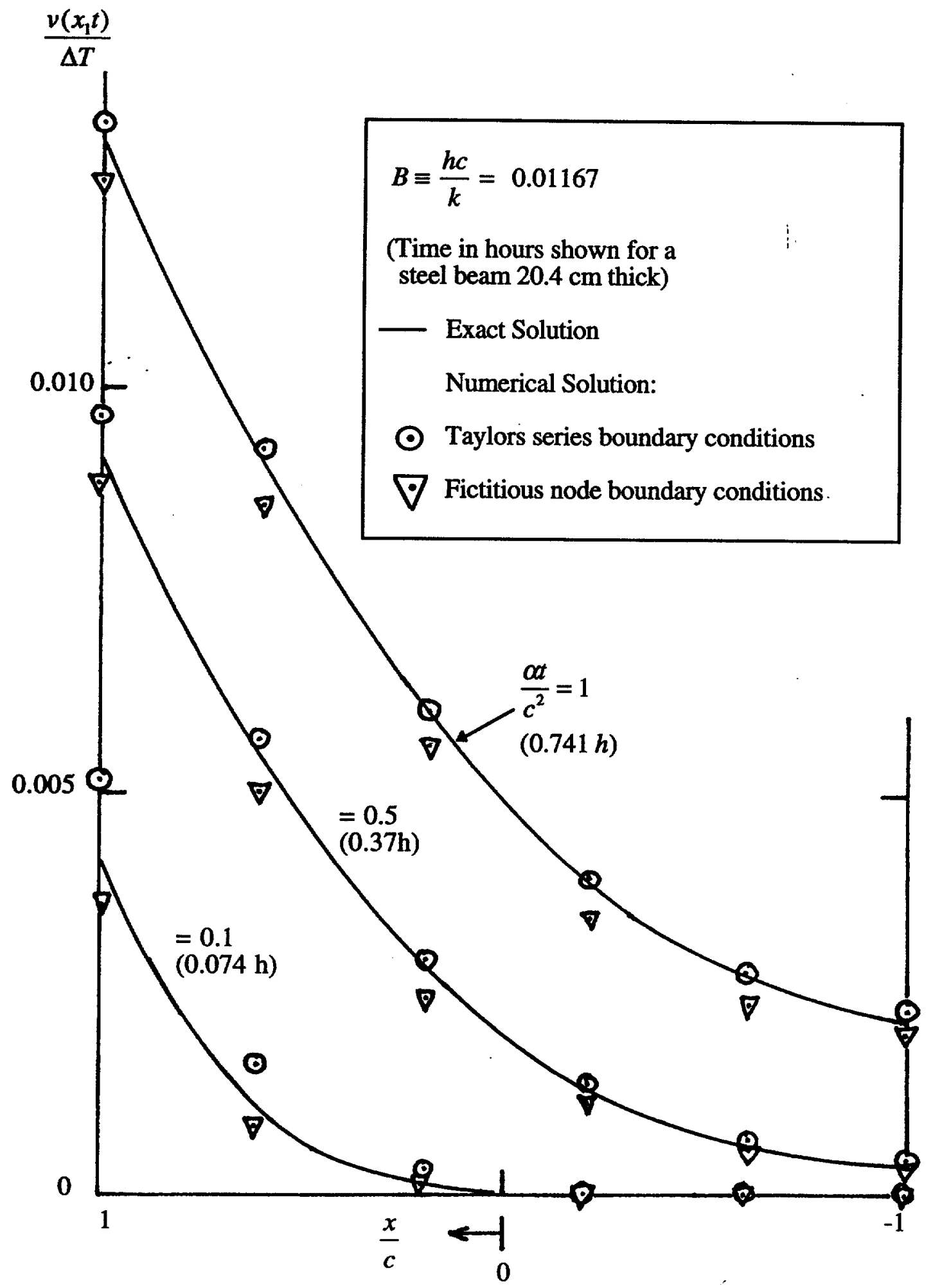


Figure 3. Difference in surface temperatures and average beam temperature

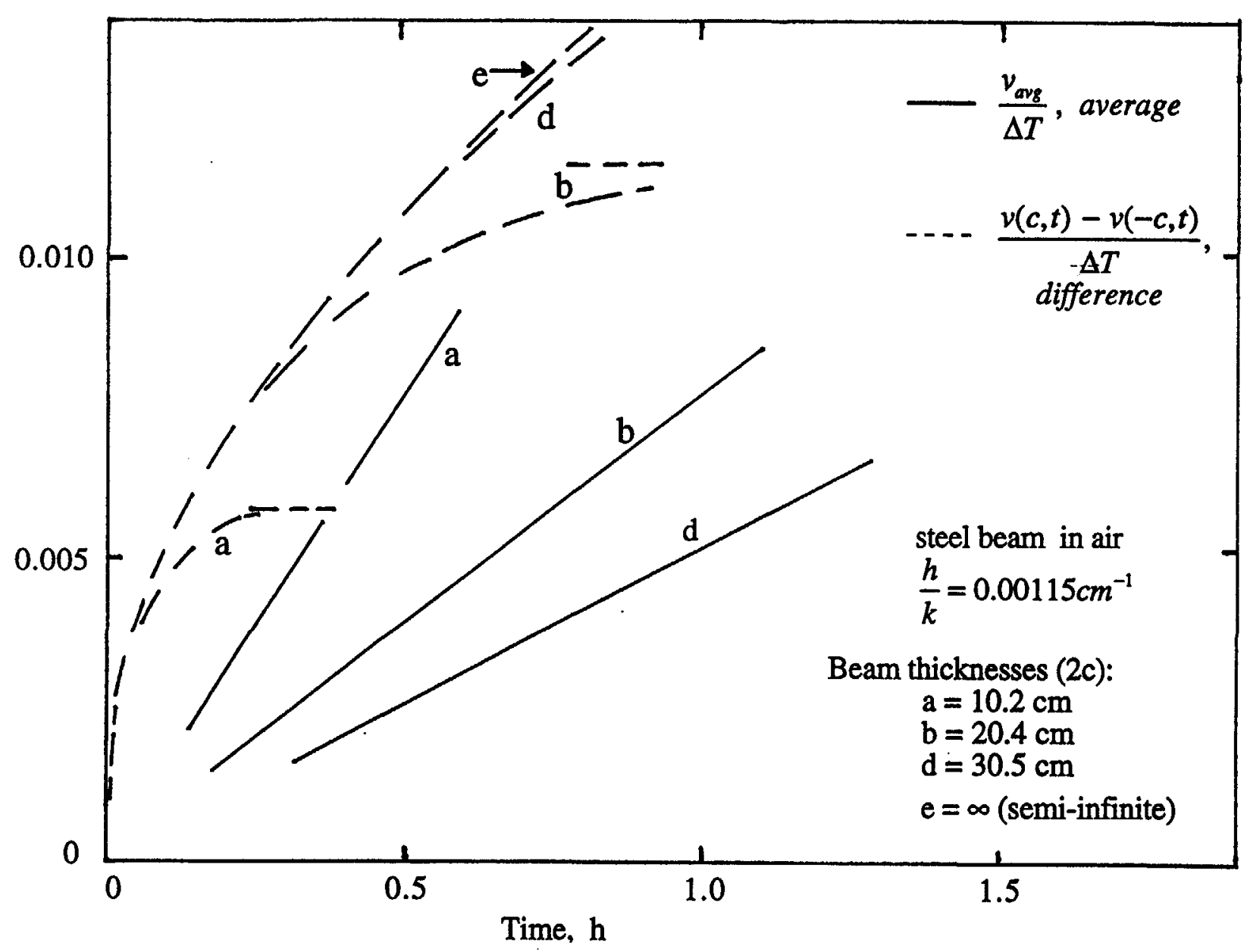


Figure 4. Deflections normalized to their steady-state values

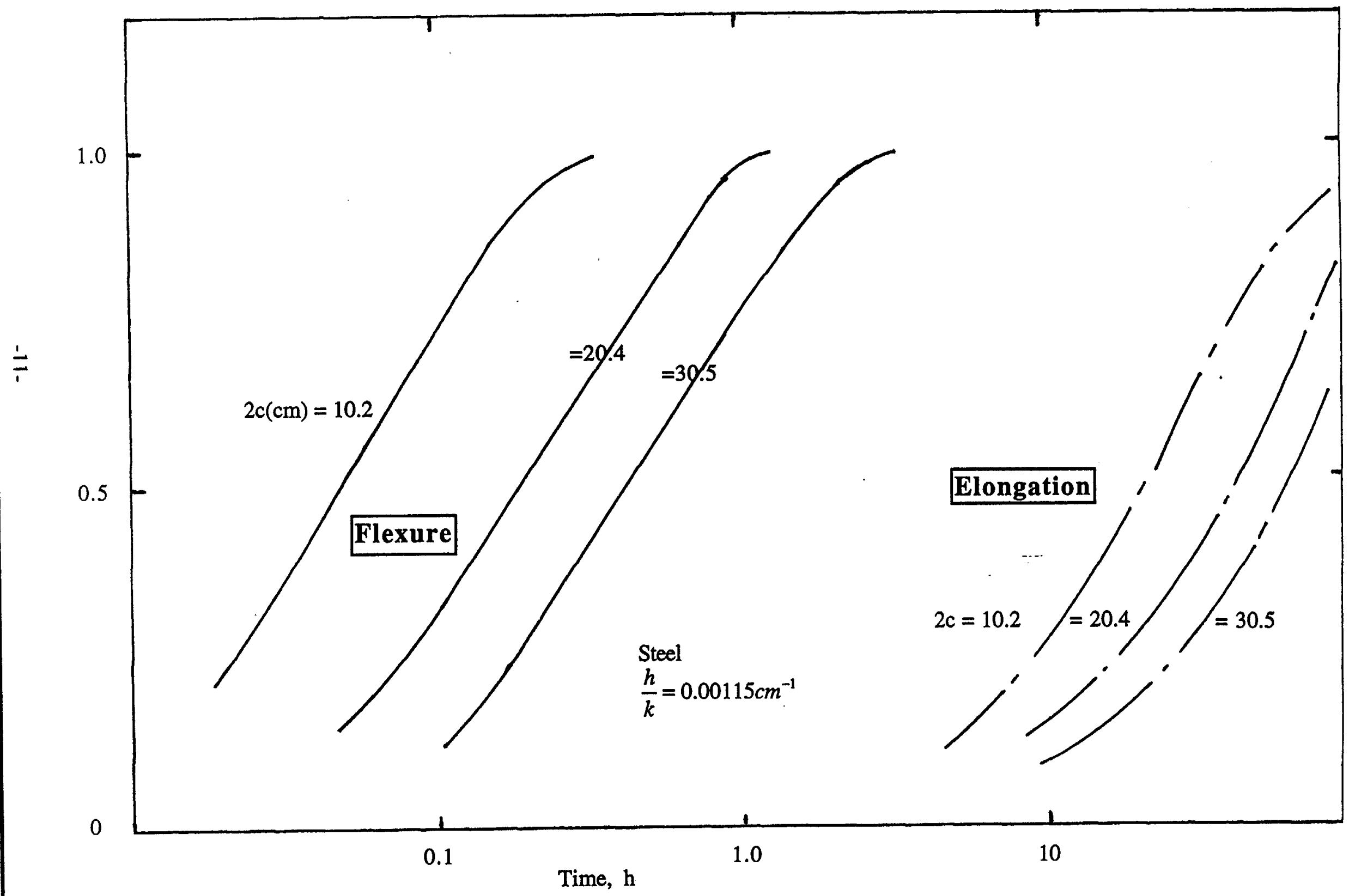


Figure 5. Steady-state deflections

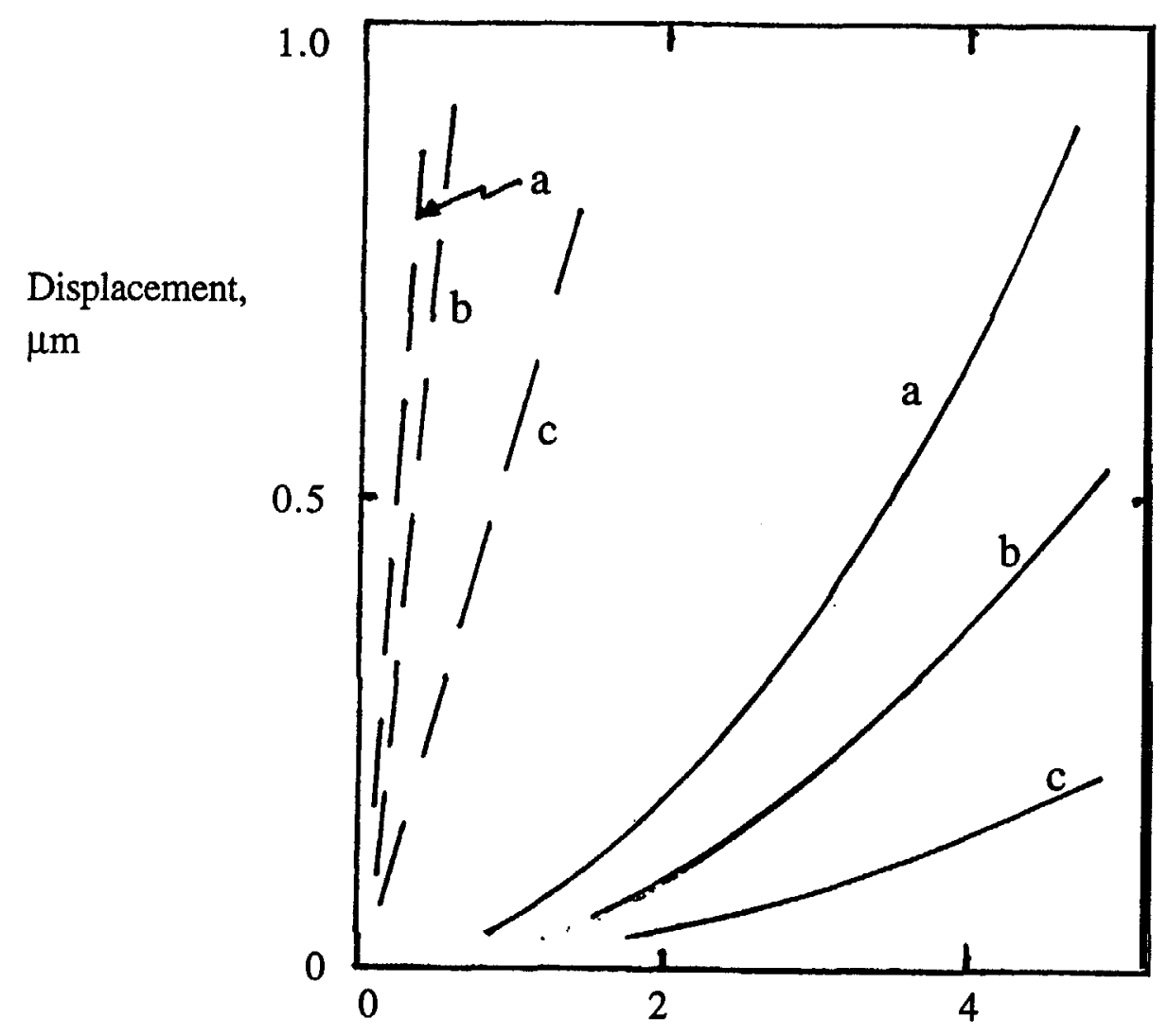

\section{- Flexure \\ -...- Elongation}

Span, L, m

eel beam with

values of $\Delta \mathrm{T}\left({ }^{\circ} \mathrm{C}\right)$ :

$$
\begin{aligned}
& a=0.5 \\
& b=0.28 \\
& c=0.10
\end{aligned}
$$


Figure 6. Beam instabilities are more significant for flexure

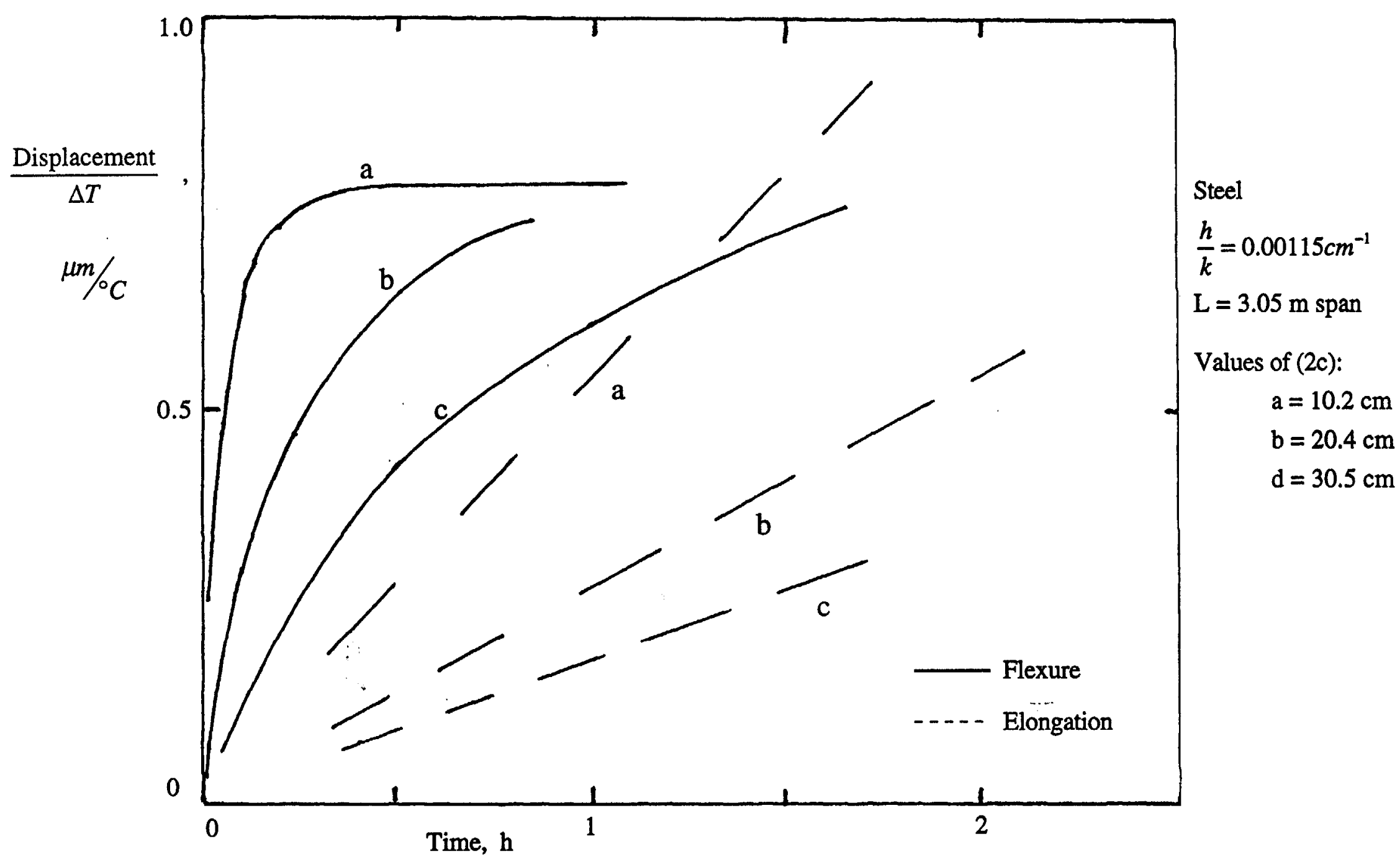




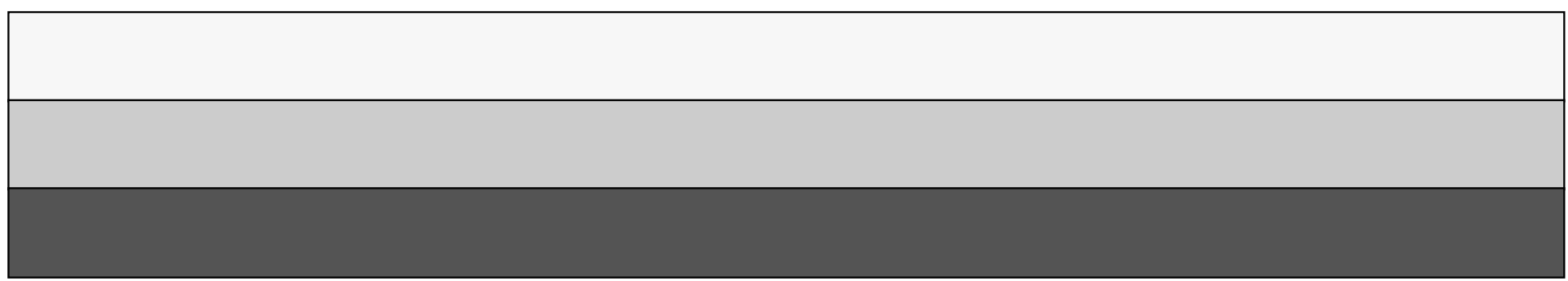

